\title{
Bidirectional Enhancement of Cell Proliferation Between Iron Oxide Nanoparticle-Labeled Mesenchymal Stem Cells and Choroid Plexus in a Cell-Based Therapy Model of Ischemic Stroke
}

This article was published in the following Dove Press journal:

International Journal of Nanomedicine

\author{
Menq-Rong $\mathrm{Wu}\left(\mathbb{D}^{1,2}\right.$ \\ Chia-Hsun Lee' \\ Jong-Kai Hsiao $\mathbb{D}^{1,3}$ \\ 'Department of Medical Imaging, Taipei \\ Tzuchi Hospital, Buddhist Tzu-Chi \\ Medical Foundation, New Taipei City \\ 23।42, Taiwan; ${ }^{2}$ Institute of Biomedical \\ Engineering, National Taiwan University, \\ Taipei 10617, Taiwan; ${ }^{3}$ School of \\ Medicine, Tzu Chi University, Hualien \\ 97004, Taiwan
}

Purpose: Stem cell therapy for ischemic stroke has shown success in experimental settings, but its translation into clinical practice is challenging. The choroid plexus (CP) plays a regulatory role in neural regeneration. Mesenchymal stem cells (MSCs) promote neurogenesis in the ventricular-subventricular zone. However, it is unclear whether MSCs interact with the CP in brain tissue repair.

Methods: Rat (r)MSCs were labeled with iron oxide nanoparticles (IONs) and transduced with red fluorescent protein, and then injected into the brain of rats with ischemic stroke and monitored over time by magnetic resonance imaging. The functional recovery of rats was determined by the corner test score, Modified Neurological Severity score, and stroke volume. MSCs and CP were also co-cultured for 14 days, and the medium was analyzed with a cytokine array.

Results: In vivo imaging and histologic analysis revealed that ION-labeled MSCs were mainly located at the injection site and migrated to the infarct area and to the CP. Functional recovery was greater in rats treated with MSCs as compared to those that received mock treatment. Bidirectional enhancement of proliferation in MSCs and CP was observed in the co-culture; moreover, MSCs migrated to the CP. Cytokine analysis revealed elevated levels of proliferation- and adhesion-related cytokines and chemokines in the culture medium. Wikipathway predictions indicated that insulin-like growth factor 1/Akt signaling (WP3675), chemokine signaling pathway (WP2292), and spinal cord injury (WP2432) are involved in the increased proliferation and migration of MSCs co-cultured with the CP.

Conclusion: Crosstalk with the $\mathrm{CP}$ enhances MSC proliferation and migration in a transwell assay. Moreover, MRI reveals MSC migration towards the $\mathrm{CP}$ in an ischemic stroke model. The secreted factors resulting from this interaction have therapeutic potential for promoting functional recovery in the brain after ischemic stroke.

Keywords: iron oxide nanoparticles, cell therapy, mesenchymal stem cell, choroid plexus, brain stroke

\section{Introduction}

Stroke is the second leading cause of death and disability worldwide. ${ }^{1}$ Preclinical studies have demonstrated the feasibility of stem cell-based therapy for restoring brain function after stroke or ischemic injury or in degenerative brain diseases. ${ }^{2,3}$ However, translation of these findings to clinical settings remains challenging, in part because of the technical difficulty of stem cell delivery and limited choice of injection sites. ${ }^{4,5}$
Department of Medical Imaging, Taipe

Tzu Chi General Hospital, Buddhist Tzu-

Chi Medical Foundation, New Taipei City

23I42, Taiwan

Tel +886-2-6628-9779-extension 6I I I4

Fax +886-2-86272976

Email jongkai@tzuchi.com.tw
International Journal of Nanomedicine 2020:15 9|8|-9|95 
Additionally, the exact localization and fate of implanted cells are not known. Iron oxide nanoparticles (IONs), one of the few types of nanoparticle that are approved for clinical applications, have been used to label mesenchymal stem cells (MSCs). ${ }^{6}$ Ferucarbotran (Bayer, Leverkusen, Germany) is an ION that has the advantage of a simple protocol for cell labeling that does not require a transfecting agent. Moreover, Ferucarbotran-labeled MSCs have the capacity for osteogenic, adipogenic, chondrogenic, and neurogenic differentiation, making them ideal candidates for cell-based therapy. ${ }^{7,8}$

Injecting MSCs into the caudate putamen near the ventricular-subventricular zone (V-SVZ) promotes neurogenesis in this area, which is the source of neurons in the adult brain. ${ }^{9,10}$ The secretome of MSCs has clinical potential for regenerative therapy in stroke. ${ }^{11}$ MSCs secrete numerous chemokines, growth factors, and cytokines such as vascular endothelial growth factor (VEGF), insulin-like growth factor (IGF)-1, basic fibroblast growth factor (bFGF), transforming growth factor (TGF)- $\beta 1$, nerve growth factor (NGF), placental growth factor, stromal-derived growth factor (SDF)-1 (also known as $\mathrm{C}-\mathrm{X}-\mathrm{C}$ motif chemokine [CXCL]12), monocyte chemoattractant protein (MCP)-1 (also known as $\mathrm{C}-\mathrm{C}$ motif chemokine ligand [CCL]2), and interleukin (IL)-6, IL-8, IL-10, and IL-13; ${ }^{12-15}$ they also secrete hepatocyte growth factor (HGF), growth and differentiation factor (GDF)-15, and IGF-binding protein (IGFBP)-5, which are involved in protection against oxidative stress. ${ }^{16-18}$ MSCs have been used in the treatment of stroke and contribute to the restoration of brain function by modulating immunity, angiogenesis, neurogenesis, and cell death. ${ }^{11,19}$ However, the optimal cell source, route and timing of administration, and microenvironment remain unknown. $^{20,21}$

Bone marrow (BM)-derived cells reportedly migrate to the leptomeninges, ${ }^{22}$ choroid plexus $(\mathrm{CP}),{ }^{23}$ and perivascular spaces $^{22}$ under noninflammatory conditions. Injected cells differentiate into glial fibrillary acidic protein-positive cells in the $\mathrm{CP}^{23}$ In the stroke brain, MSCs are detected at the infarct and injection sites and in the corpus callosum (CC) ${ }^{24-26}$ MSCs in the hippocampus and $\mathrm{CP}$ with ependymal cell features have been identified in Alzheimer mouse models. ${ }^{27}$ There is increasing evidence for the regulatory role of the $\mathrm{CP}$ in the brain. The CP produces cerebrospinal fluid (CSF) in the $\mathrm{V}-$ SVZ and promotes the proliferation of neural stem cells via secreted factors ${ }^{28}$ involved in tissue maintenance and repair such as TGF- $\beta$, GDF-15, glial cell line-derived neurotrophic factor (GDNF), IGF-2, NGF, neurotropin (NT)-3, NT-4, brain-derived neurotrophic factor (BDNF), VEGF, and FGF2. ${ }^{29-31}$ Furthermore, immune cells are recruited by the chemokines CCL2, CXCL8, CX3CL1, CCL18, CCL4, CCL15, CCL22, CCL20, X-C motif chemokine ligand 1, CCL18, CCL24, CCL3, CCL25, CXCL11, CCL19, CXCL12, and CCL5 secreted by the $\mathrm{CP}^{32}$ Thus, the $\mathrm{CP}$ is involved in immunomodulation and cell trafficking ${ }^{32}$ and plays a neuroprotective role after stroke, ${ }^{33,34}$ although it is unclear whether or how it interacts with MSCs.

To evaluate the applicability of MSCs to the treatment of stroke, the present study investigated the interaction between MSCs and CP using a rat stroke model.

\section{Materials and Methods \\ Red Fluorescent Protein (RFP) Transduction and Cell Culture}

The psPAX2, pMD2G, and pLAS5w.PtRFP-I2-Puro plasmids (RNAi Core at Academia Sinica, Taipei, Taiwan) were mixed with PolyJet (SignaGen, Rockville, MD, USA) and added to the culture medium of human embryonic kidney (HEK) 293T cells (purchased from ATCC) harboring a plasmid encoding a temperature-sensitive mutant of the SV40 large T antigen (a gift from MingJuim Shieh, National Taiwan University) for RFP lentivirus production. ${ }^{35}$ RFP lentiviruses were transduced into MSCs isolated from the BM of Sprague-Dawley rats at a multiplicity of infection of 50. Clones were cultured in medium containing $2 \mu \mathrm{g} / \mathrm{mL}$ puromycin (Millipore, Billerica, MA, USA) for 1 week. RFP+ rat (r)MSCs were labeled with antibodies against CD29, CD90, CD45, and CD 11b/c (all from BioLegend, San Diego, CA, USA) and sorted by flow cytometry on a FACSCalibur instrument (BD Biosciences, San Jose, CA, USA) with an allophycocyanin-A filter. The HEK 293T cells and rMSCs were cultured in Dulbecco's Modified Eagle's medium (DMEM; Thermo Fisher Scientific, Waltham, MA, USA) containing $10 \%$ fetal bovine serum (Biologic Industries, Cromwell, CT, USA), $100 \mathrm{U} / \mathrm{mL}$ penicillin, and $100 \mathrm{mg} / \mathrm{mL}$ streptomycin (Thermo Fisher Scientific) at $37^{\circ} \mathrm{C}$ in a humidified atmosphere of $5 \% \mathrm{CO}_{2}$.

\section{ION Labeling}

RFP+ rMSCs $\left(10^{6}\right)$ were seeded in a $10-\mathrm{cm}^{2}$ dish and cultured overnight before $10 \mathrm{mg}$ Fe/mL Ferucarbotran 
was added for $24 \mathrm{~h}$. Cells were washed 3 times with $1 \times$ phosphate-buffered saline (PBS) to remove unbound Ferucarbotran and dissociated with trypsin for injection. ${ }^{8}$

\section{Brain Stroke Model and RFP+ rMSC Injection}

All animal procedures were approved by the Institutional Animal Care and Use Committee of Taipei Tzuchi General Hospital (IACUC no. 105-IACUC-003) and were carried out in accordance with the updated Guiding Principles for the Care and Use of Vertebrate Animals in Research and Training. ${ }^{36}$ The bilateral common carotid artery of anesthetized male rats aged 6-8 weeks was exposed by shaving the neck hair, sterilizing the skin with $70 \%$ alcohol, and making an incision in the skin and subcutaneous tissue and muscle. The rats were immobilized in a stereotactic frame, and the skull in the right retroorbital region was removed. The right middle cerebral artery (MCA) infarct model was established by ligating the right MCA with a 10-0 nylon suture. Bilateral carotid arteries were also ligated for $90 \mathrm{~min}$ with surgical clips. After $90 \mathrm{~min}$, the suture and clips were removed to induce reperfusion injury. In the cell therapy group, $10^{6} \mathrm{ION}$ labeled MSCs in $10 \mu \mathrm{L}$ saline were locally injected into the right $\mathrm{CC} 1 \mathrm{~h}$ after the ischemia-reperfusion procedure at the following stereotactic coordinates: anterior-posterior, $0 \mathrm{~mm}$; medial--lateral, $2.0 \mathrm{~mm}$; and dorsal-ventral, $3 \mathrm{~mm}$. The control group was injected with $10 \mu \mathrm{L}$ saline by the same procedure as that used for cell injection.

\section{Behavioral Analysis After Ischemia- Reperfusion Injury}

Modified Neurological Severity score (mNSS) assessment and the corner test were performed weekly after ischemiareperfusion injury by an experienced investigator who was blinded to the experimental design during testing. The mNSS evaluates the sensory and motor aspects of brain function. ${ }^{37,38}$ Rats that failed in the walking, righting, placing, balance, and body resistance tests were assigned a score of 1 ; scores of 1-6, 7-12, and 13-18 indicated mild, moderate, and severe injury, respectively, with a score of 18 indicating maximum disability.

Sensorimotor disability after ischemia-reperfusion injury was evaluated with the corner test. ${ }^{39}$ Briefly, the rat was positioned in front of 2 boards angled at $30^{\circ}$; when it walked into the corner, vibrissae stimulation was applied to direct the rat to turn or rear to one side (right or left).
Normal rats turned or reared at equal frequencies to the left and right but rats with right MCA occlusion turned more frequently to the right side because of a loss of vibrissae sensation and left-side rearing disability. Each rat was evaluated weekly after the surgery up to 15 times. A score of 7 indicated no neurologic deficit, whereas a score of 15 indicated severe sensorimotor disability.

\section{In vivo Magnetic Resonance Imaging (MRI)} ION-labeled RFP+ rMSCs were visualized by MRI 35 days after MCA occlusion surgery. Rats were anesthetized with isoflurane, and T2 images were acquired using a 7T MRI system (Biospec 70/30; Bruker, Ettlingen, Germany) with the following parameters: repetition time/echo time $=5000 / 56 \mathrm{~ms}$; resolution $=256 \times 256$ pixels; slice thickness $=5 \mathrm{~mm}$; and field of view $=30 \times 30 \mathrm{~cm}^{2}$. Initial infarct volume differed across rats and was normalized to compare the recovery of stroke volume, which was calculated as $\left(100-\left[\mathrm{DX}\right.\right.$ stroke volume $\left.\left./ \mathrm{D} 1_{\text {stroke volume }}\right]\right)$.

\section{Histology and Prussian Blue (PB) Staining}

Rat brains were collected at poststroke day 35 and embedded in paraffin for sectioning at a thickness of 5 $\mu \mathrm{m}$. After serial rehydration, sections were incubated with PB (Millipore) for $20 \mathrm{~min}$ and then counterstained with nuclear fast red (Millipore) for $5 \mathrm{~min}$ before light microscopy observation.

\section{$\mathrm{CP}$ Isolation}

The CP was isolated from 6-week-old rats that were not injected with rMSCs. The brain was placed with the dorsal side facing upward and fixed using a clamp. Another clamp was placed across the midline of the hemisphere, penetrating the cortex and $\mathrm{CC}$ in the lateral ventricle (approximately 3.3-mm deep). A twister was used to clamp the $\mathrm{CC}$ and strip it from the lateral ventricle. The isolated $\mathrm{CP}$ was treated with $0.75 \%$ collagenase II at $37^{\circ} \mathrm{C}$ with rotation at $20 \mathrm{rpm}$ for 30-60 min. After enzymatic digestion, the tissue was centrifuged at $1500 \mathrm{rpm}$ at $4^{\circ} \mathrm{C}$ for $10 \mathrm{~min}$ and washed 3 times with $1 \times$ PBS. The collected cells were cultured in DMEM/F12 (1:1) containing 10\% fetal bovine serum, $4 \mathrm{mM}$ L-glutamine, $5 \mu \mathrm{g} / \mathrm{mL}$ insulin, $200 \mathrm{ng} / \mathrm{mL}$ hydrocortisone, $20 \mu \mathrm{M}$ cytosine arabinoside, $100 \mathrm{~g} / \mathrm{mL}$ penicillin/streptomycin, and $10 \mathrm{ng} / \mathrm{mL}$ epidermal growth factor. 


\section{Co-Culture of rMSCs and CP}

To assess the pro-proliferative effect of the CP on rMSCs, $3 \times 10^{3}$ rMSCs were seeded on a $50 \mu \mathrm{g} / \mathrm{mL}$ laminin-coated transwell membrane (Costar, Cambridge, MA, USA). The well beneath the membrane was seeded with $0.027 \mathrm{~g} \mathrm{CP}$ or filled with culture medium only as a negative control. To evaluate the reverse effect (ie, the ability of rMSCs to induce proliferation in the $\mathrm{CP}$ ), $8 \times 10^{3} \mathrm{rMSC}$ were seeded in the well and $0.027 \mathrm{~g} \mathrm{CP}$ was placed on the $50 \mu \mathrm{g} / \mathrm{mL}$ laminin-coated transwell membrane. After 14 days of coculture, the samples were stained with $10 \%$ crystal violet for $30 \mathrm{~min}$ and crystals were dissolved in dimethylsulfoxide. The optical density was measured using a Spark 10M spectrophotometer (Tecan, Männedorf, Switzerland). Cell migration was evaluated using the same protocol except that cells on the inner surface of the transwell membrane were removed with a cotton swab before crystal violet staining.

\section{Cytokine Profiling}

After co-culture of the CP and RFP+ rMSCs for 14 days, the medium was collected and hybridized with the membrane from the Proteome Profiler Array Rat XL Cytokine Array Kit (ARY030; R\&D Systems, Minneapolis, MN, USA). Signals were detected using the BioSpectrum 810 Imaging System (UVP, Upland, CA, USA) and quantified using ImageJ software. ${ }^{40}$ Data were further analyzed using ClustVis software. ${ }^{41}$ Principal component analysis (PCA) and heatmap analysis were performed by row centering, unit variance, and singular value decomposition with imputation. The heatmap is shown with the collapsed columns median. Pathways potentially involved in the interaction between the $\mathrm{CP}$ and MSCs were predicted with Enrichr ${ }^{42,43}$ using the following input genes: $H G F$, IGFBP-3, IGFBP-5, GDF-15, CCL5, CXCL2, nephroblastoma overexpressed $(\mathrm{NOV}) /$ cellular communication network factor $(C C N) 3$, WNT1-inducible signaling pathway protein (WISP)-1/CCN4, CCL22, lectin, galactosidebinding, soluble (LGALS)1 (galectin-1), and intercellular adhesion molecule $(I C A M) 1$.

\section{Statistical Analysis}

Data are expressed as mean \pm standard error and were analyzed using Prism v5 software (GraphPad, La Jolla, CA, USA). Means were compared by 1-way analysis of variance and Tukey's multiple comparisons test. Indices of functional recovery including mNSS, corner test score, and stroke volume were analyzed by linear regression. Data at each time point were analyzed with the Student's $t$-test. $\mathrm{P}<0.05$ was considered statistically significant.

\section{Results}

\section{Stemness of rMSCs}

As viral transduction can alter normal cellular functions, we evaluated the stemness of rMSCs by flow cytometry. The isotype control antibody was detected at very low levels $(<0.1 \%)$ in control rMSCs and RFP+ rMSCs, indicating that the labeling of cluster of differentiation (CD) 29, CD90, CD45, and CD11b/c was reliable (Figure S1A). Expression of the positive markers CD29 and CD90 was observed in $>99.9 \%$ of control rMSCs and RFP+ rMSCs (Figure S1B, C), whereas that of the negative markers CD45 and CD 11b/c was detected in $<1.04 \%$ (Figure $\underline{\mathrm{S} 1 \mathrm{D}, \mathrm{E})}$. These data indicate that RFP+ rMSCs retained their stem cell identity (Figure S1).

\section{Distribution of Injected RFP+ rMSCs in Stroke Brain}

To assess the destination of rMSCs in the stroke brain, RFP+ rMSCs were labeled with IONs prior to injection and their localization in the infarct area was examined by MRI (Figure 1A). Bright regions showed decreased signal intensity after stroke and RFP+ rMSC injection (Figure 1A). The deep dark regions corresponded to the ION signal (Figure 1A). A shift in the ION signal from the injection site was detected by MRI on day 8 or early on day 1 in ION-RFP+ rMSC-treated group (Figures $1 \mathrm{~A}$ and 2). This was confirmed by $\mathrm{PB}$ staining of the $\mathrm{CP}$ and infarct site (Figure 1B). The ION signal detected by MRI was mainly located at the ipsilateral lateral ventricle $(68 \%)$, third ventricle $(41 \%)$, injection site $(32 \%)$, and contralateral lateral ventricle (27\%) (Figure 2 and Table 1). In PB staining, the percentage distribution was $33 \%$ at the injection site, $33 \%$ at the infarct site, $22 \%$ in the $\mathrm{CP}, 11 \%$ in the $\mathrm{CC}$, and $11 \%$ in the cerebellum (Table 2). Functional recovery was observed after injection of rMSCs, with improvements in mNSS and corner test score (Figure $3 \mathrm{~A}$ and B). However, stroke volume recovery rate did not differ significantly between the saline- and ION-RFP+ rMSC-treated groups (Figure 3C).

\section{Bidirectional Interaction Between RFP+ rMSCs and CP}

We next evaluated the interaction between co-cultured rMSCs and CP with the transwell assay. Proliferation 


\section{A}

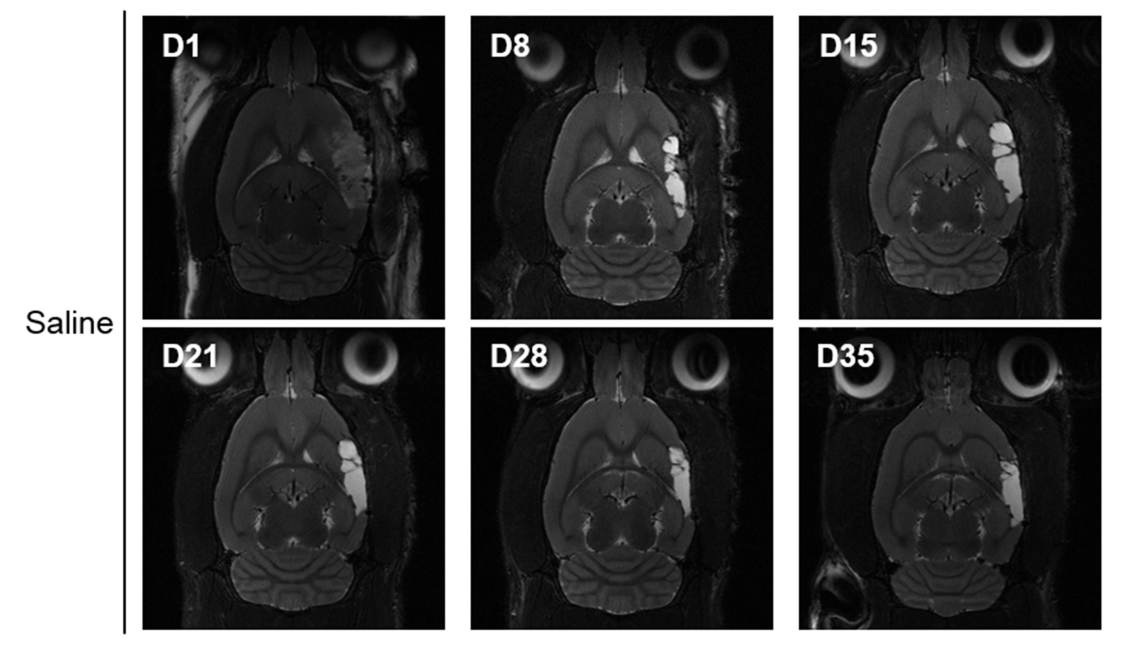

ION-RFP+ rMSC
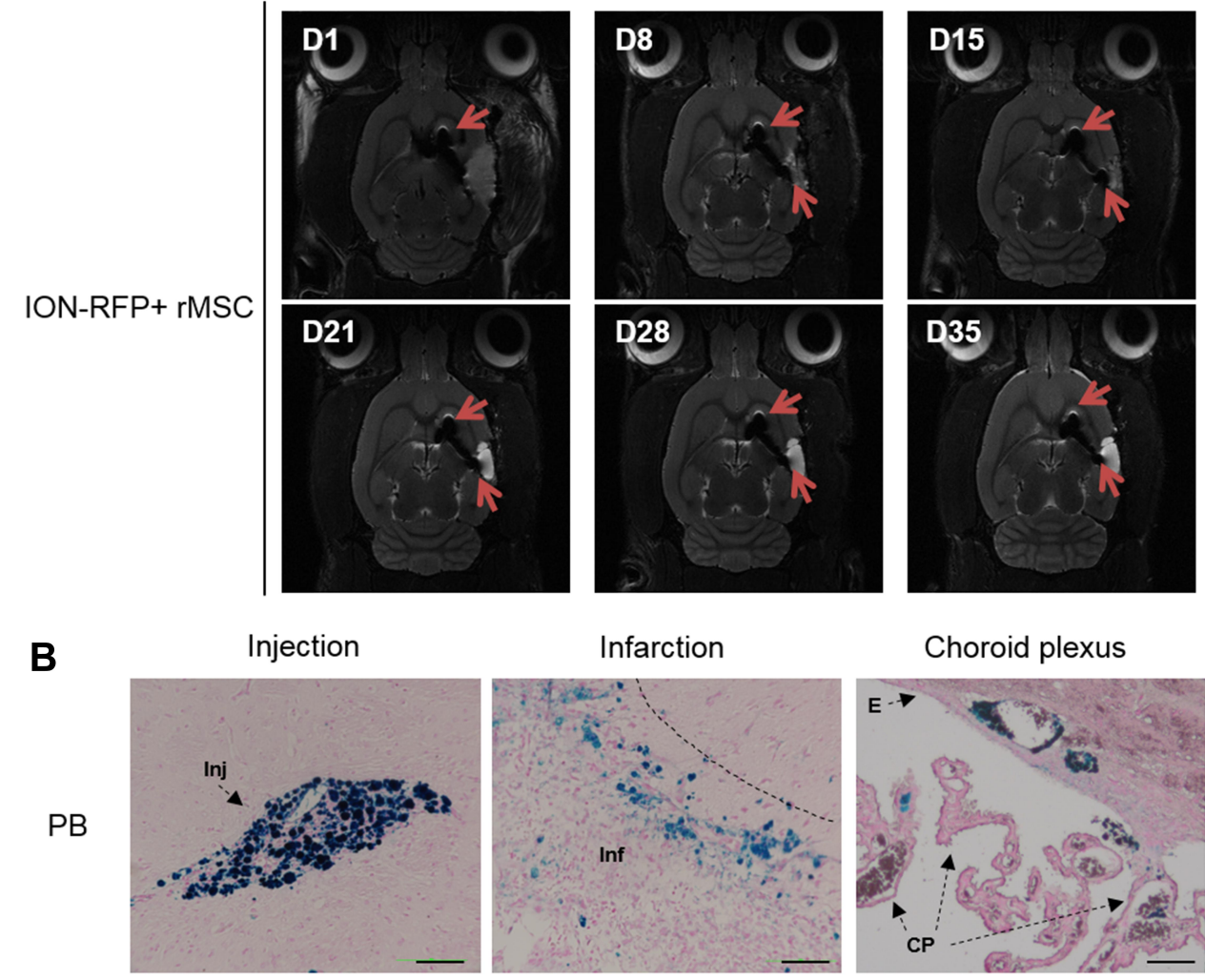

\section{Choroid plexus}
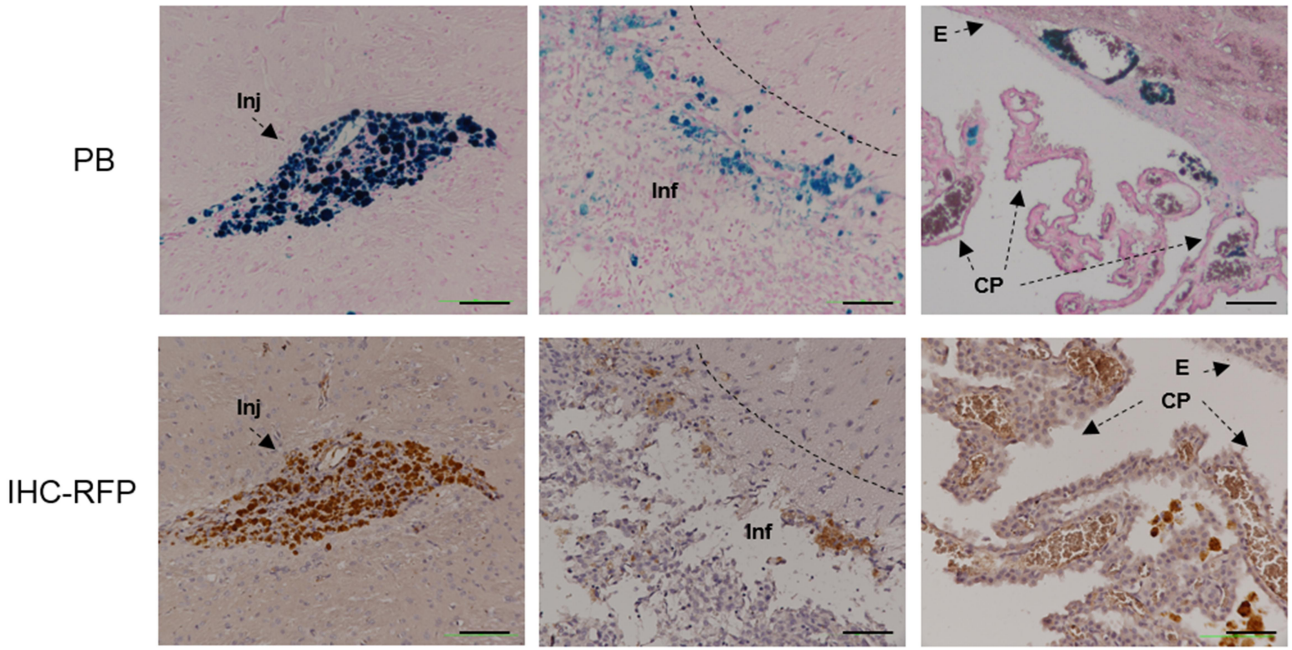

Figure I Localization of ION-labeled RFP+ rMSCs in stroke brain detected by MRI and PB staining. (A) Sequential MRI scans at poststroke days I, 8, I5, 2I, 28, and 35. (B) PB staining and RFP immunohistochemistry (IHC) of specific regions (injection site, infarct site, and CP) on poststroke day 35 . Scale bar: I00 $\mu$ m. Red arrowheads: ION signal.

Abbreviations: E, ependymal layer; Inf, infarct region; Inj, injection site. 
Frame 5
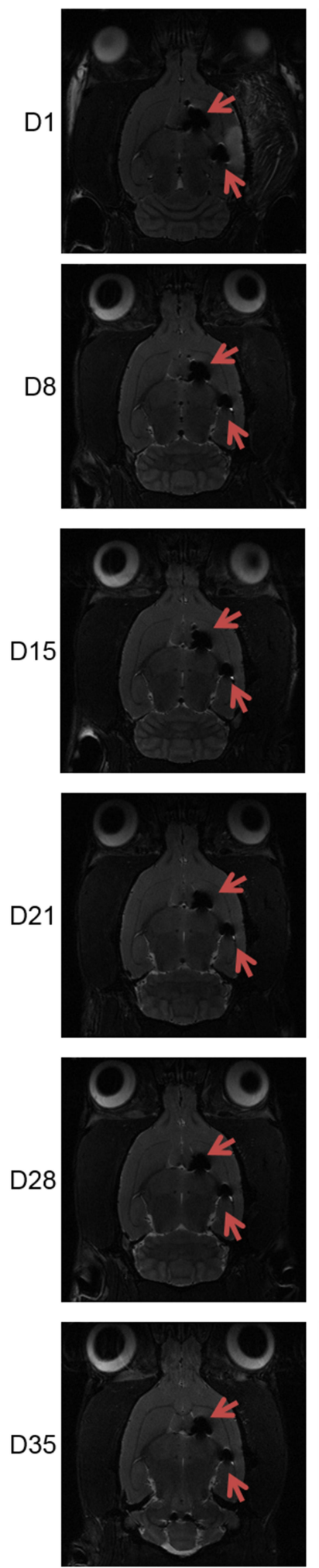

Frame 7
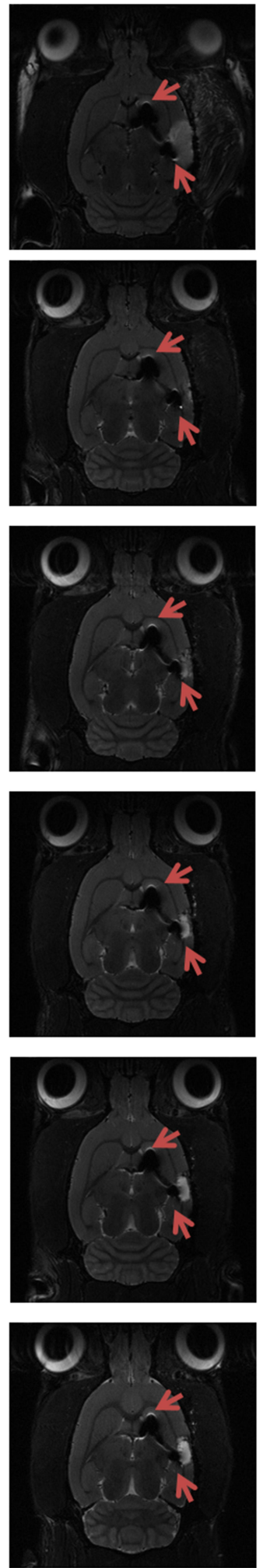

Frame 9
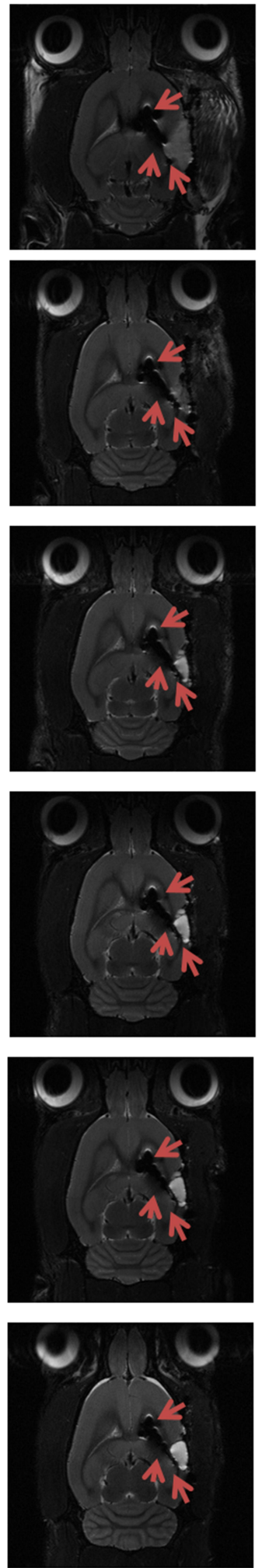

Frame 11
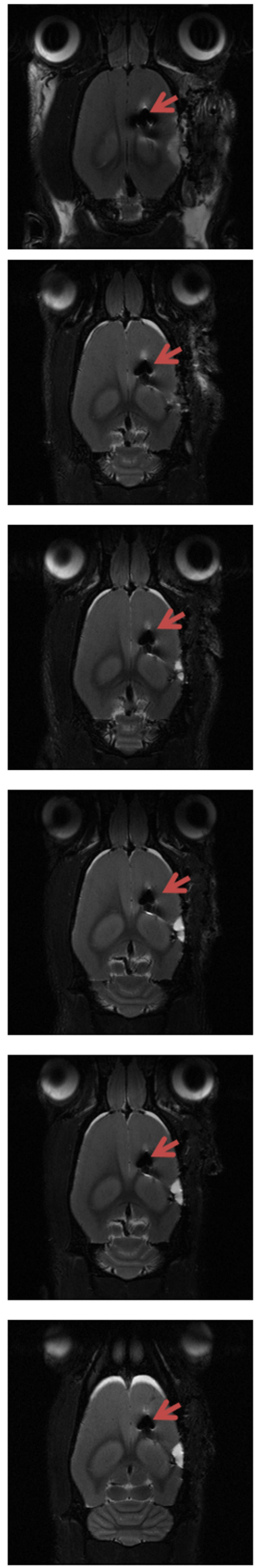

Figure 2 Spatial and temporal resolution of ION signals in stroke brain after ION-labeled RFP+ rMSC injection. Red arrowheads: ION signal. 
Table I Distribution of Iron Oxide Nanoparticle Signals in the Brain Detected by Magnetic Resonance Imaging $(\mathrm{N}=22)$

\begin{tabular}{|l|l|}
\hline Brain Area & Percentage \\
\hline Injection site & $32 \%$ \\
Ipsilateral ventricle & $68 \%$ \\
Contralateral ventricle & $27 \%$ \\
Third ventricle & $41 \%$ \\
\hline
\end{tabular}

promotion was observed in both the rMSCs (Figure 4A and $\mathrm{E}$ ) and $\mathrm{CP}$ (Figure 4B and F). Additionally, rMSC migration was stimulated in the co-culture with the $\mathrm{CP}$ (Figure 4C), but not in the CP (Figure 4D). Thus, a bidirectional interaction exists between MSCs and CP that enhances proliferation in both.

\section{Cytokine Profile of RFP+ rMSC and CP Co-Cultures}

We investigated the factors mediating the interaction between rMSCs and CP by cytokine profiling of the medium from co-cultures collected on day 14. Four groups were compared: $\mathrm{C} / \mathrm{M}$ (CP on top and RFP+ rMSCs on the bottom), M/C (RFP+ rMSCs on top and $\mathrm{CP}$ on the bottom), $\mathrm{M} / \mathrm{X}$ (RFP+ rMSCs on top, with no $\mathrm{CP}$ ), and $\mathrm{X} / \mathrm{C}$ (no MSCs, with CP on the bottom) (Figure 5A). The PCA results showed that $\mathrm{X} / \mathrm{C}$ was independent of the other groups; although $\mathrm{C} / \mathrm{M}, \mathrm{M} / \mathrm{C}$, and $\mathrm{M} / \mathrm{X}$ showed overlap, they were still distinguishable from each other, suggesting that the dominant cytokines were derived from rMSCs (Figure 5B). There were 3 clusters in the heatmap (Figure $5 \mathrm{C}$ ). $\mathrm{C} 1$ was generally highly expressed in $\mathrm{X} / \mathrm{C}$, $\mathrm{C} 2$ in $\mathrm{M} / \mathrm{X}$, and $\mathrm{C} 3$ in $\mathrm{C} / \mathrm{M}$ and $\mathrm{M} / \mathrm{C}$ (Figure $5 \mathrm{C}$ ). A comparison of cytokines in $\mathrm{C} 3$ revealed that those related to proliferation - namely, HGF, IGFBP-3, IGFBP5, and GDF-15-differed significantly between $\mathrm{X} / \mathrm{C}$ and $\mathrm{C} / \mathrm{M}$ (Figure $6 \mathrm{~A}-\mathrm{C}$ and $\mathrm{F}$ ). The levels of the chemokines CCL5, CXCL2, NOV/CCN3, WISP-1/CCN4, and CCL22 differed between groups (Figure 6D, E, and G-I); and the

Table 2 Distribution of Iron Oxide Nanoparticles in the Brain Detected by Prussian Blue Staining ( $\mathrm{N}=9)$

\begin{tabular}{|l|l|}
\hline Brain Area & Percentage \\
\hline Injection site & $33 \%$ \\
Infarct site & $33 \%$ \\
Choroid plexus & $22 \%$ \\
Corpus callosum & $11 \%$ \\
Cerebellum & $11 \%$ \\
\hline
\end{tabular}

A

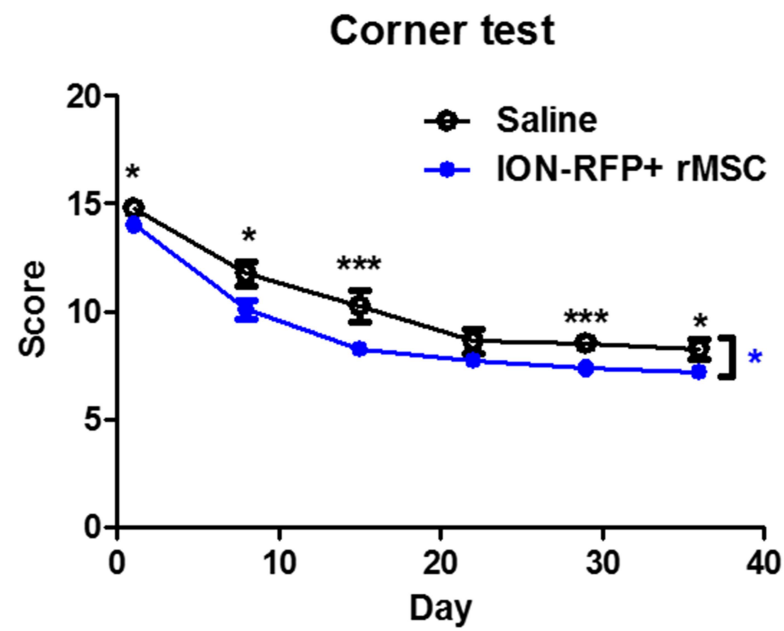

B mNSS
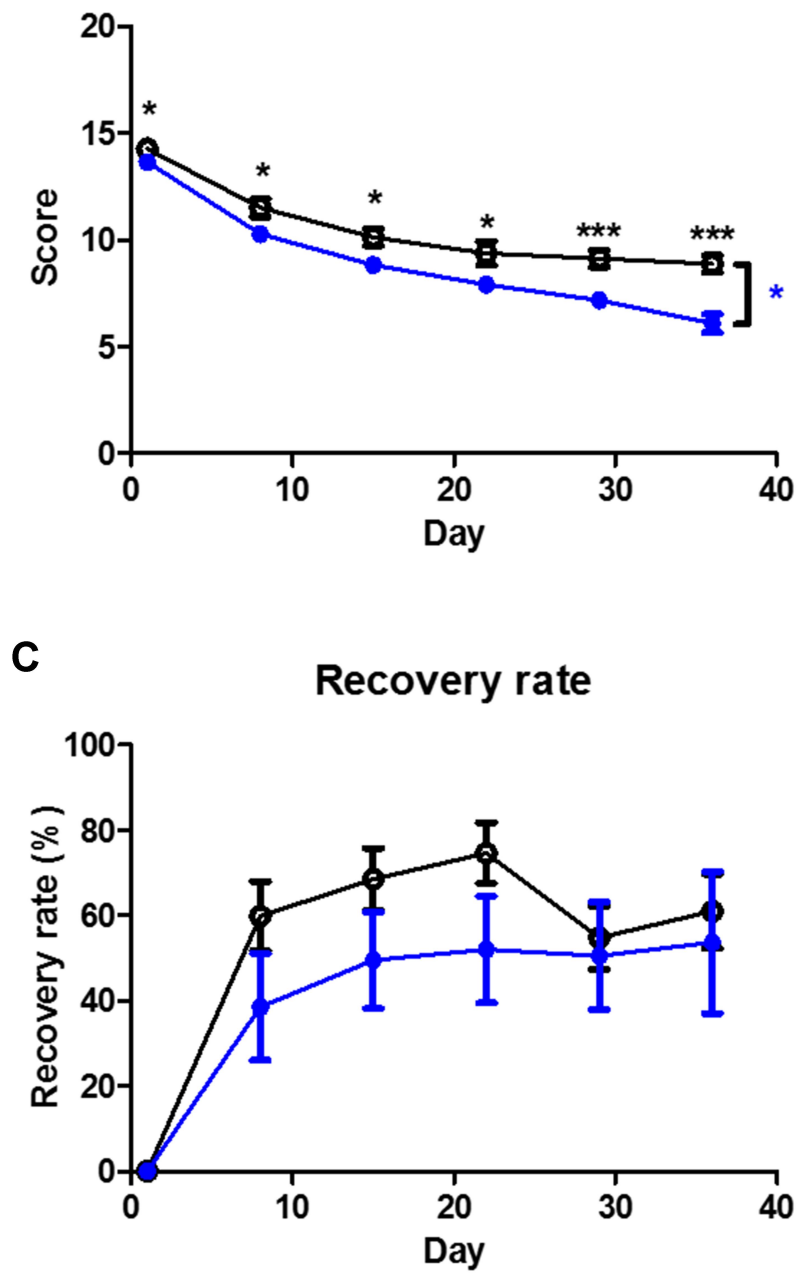

Figure 3 Indices of functional recovery. (A) Corner test score. (B) mNSS score. (C) Recovery rate of stroke volume $\left(100-\left[D X_{\text {stroke volume }} / D I_{\text {stroke volume }}\right]\right)$ at indicated time points after ischemia. Error bars represent SEM ( $N=6$ and II in saline and ION-RFP+ rMSC groups, respectively).* with blue color $\mathrm{P}<0.05$ (by linear regression). * with black color $\mathrm{P}<0.05$, *** with black color $\mathrm{P}<0.00$ I (by Student's t-test). 

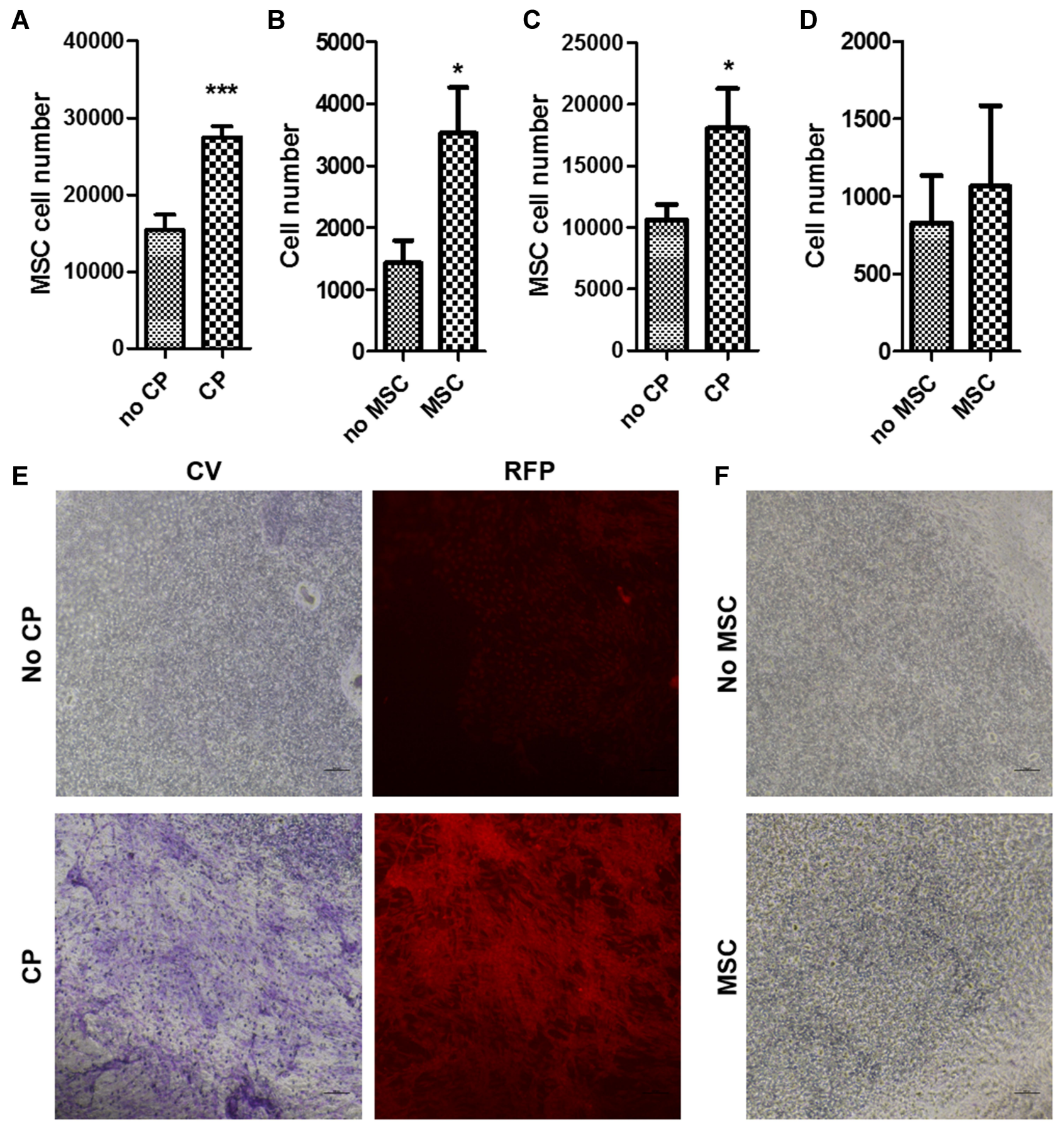

Figure 4 Interaction between RFP+ rMSCs and CP. (A, C) Proliferation (A) and migration (C) of RFP+ rMSCs with or without CP co-culture. (B, D) Proliferation (B) and migration (D) of CP cells with or without RFP+ rMSC co-culture. (E) Crystal violet staining and RFP intensity for (A). (F) Crystal violet staining for (B). Error bars represent $\mathrm{SEM}$ ( $\mathrm{N}=6$ per group). ${ }^{*} \mathrm{P}<0.05,{ }^{*} * \mathrm{P}<0.00 \mathrm{I}$.

levels of NOV, WISP-1, and CCL22 in C/M and M/C differed significantly from those in $\mathrm{M} / \mathrm{X}$ and $\mathrm{X} / \mathrm{C}$ (Figure $6 \mathrm{G}-\mathrm{I})$. The levels of cytokines involved in adhesion-ie, galectin-1 and ICAM1-differed significantly between $\mathrm{X} /$ $\mathrm{C}$ and $\mathrm{C} / \mathrm{M}$ (Figure $6 \mathrm{~J}$ and $\mathrm{K}$ ).
Pathways Involved in the Interaction Between RFP+ rMSCs and CP

The signaling pathways involved in the interaction between rMSCs and CP were predicted with Enrichr using the following input genes: $C X C L 2, C C L 5, C C L 22, I G F B P 3, I G F B P 5$, 

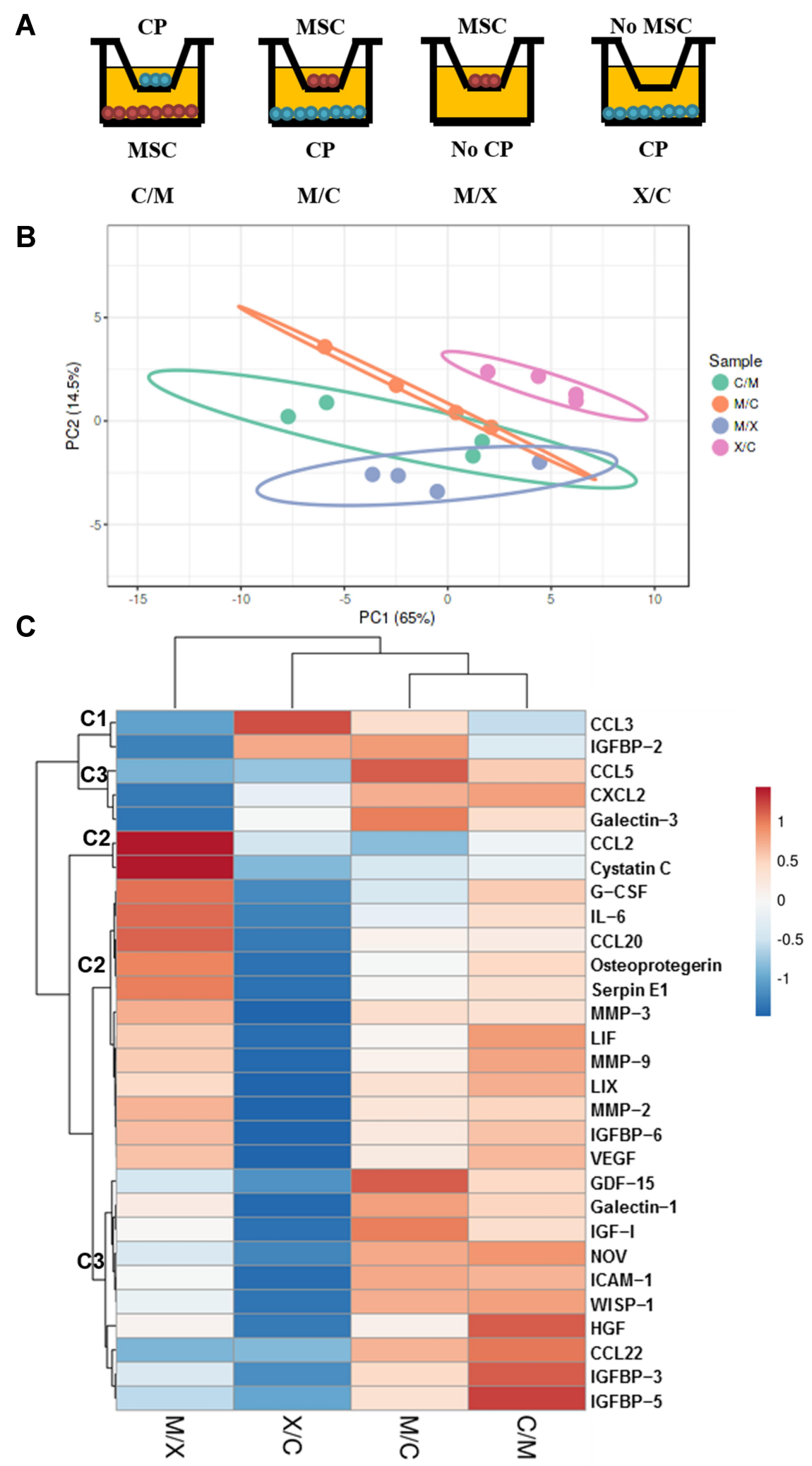

Figure 5 Cytokine profile on day 14 of RFP+ MSC and CP co-culture. (A) Illustration of different groups. (B) PCA. (C) Heatmap showing 3 clusters (Cl, C2, and C3). M/C: Top and bottom sides cultured with RFP+ rMSCs and CP, respectively. C/M: Top and bottom sides cultured with CP and RFP+ rMSCs, respectively. M/X: Top and bottom sides cultured with RFP+ rMSCs and no CP, respectively. X/C: Top and bottom sides cultured with no rMSCs and CP, respectively. $N=4$ per group. 

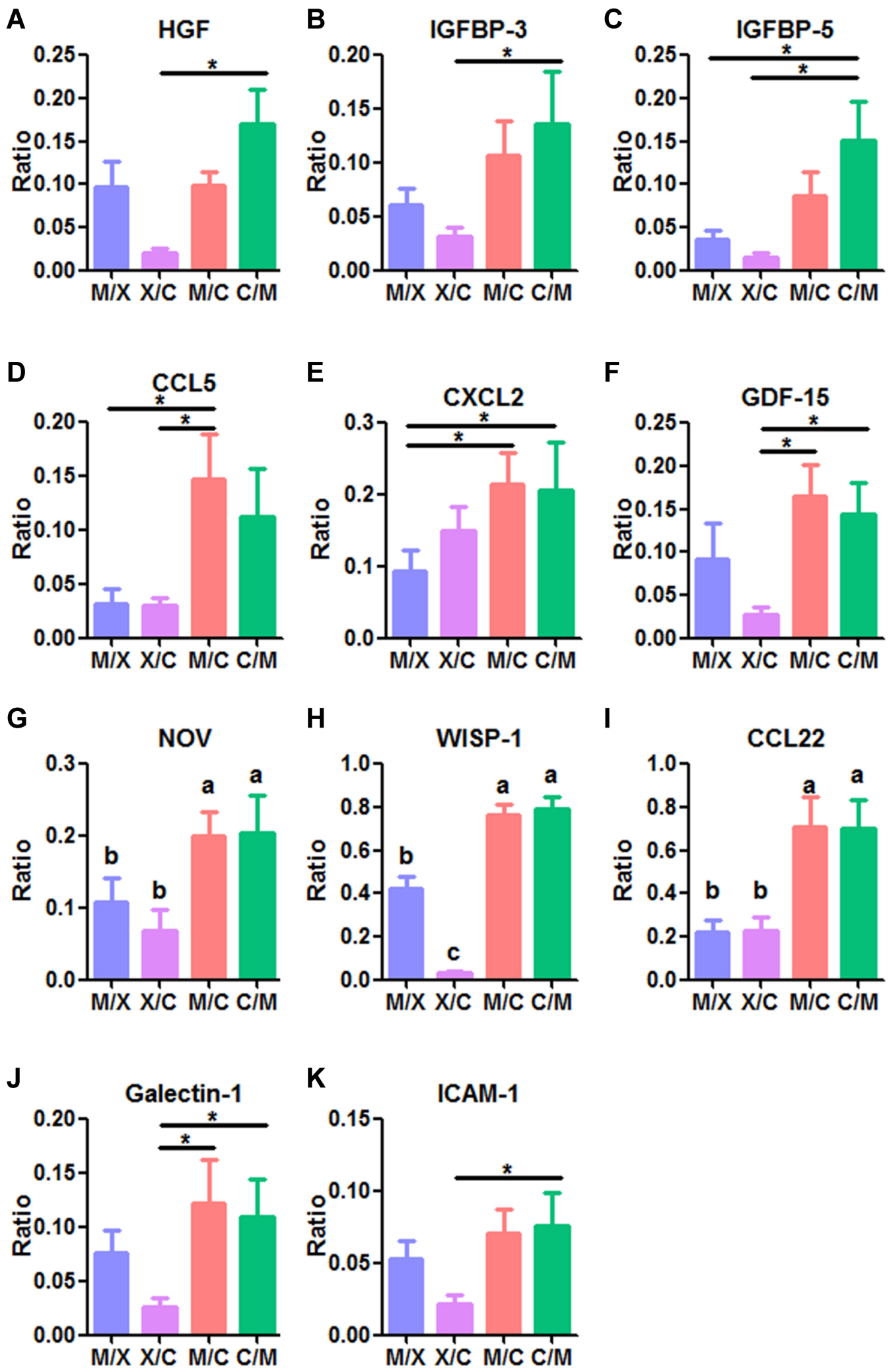

Figure 6 Levels of secreted cytokines identified in the bioinformatics analysis on day 14 of RFP+ rMSC and CP co-culture. Proliferation-related cytokines: (A) HGF, (B) IGFBP-3, and (C) IGFBP-5. Chemokines: (D) CCL5, (E) CXCL2, (F) GDF-I5, (G) NOV, (H) WISP-I, and (I) CCL22. Adhesion-related cytokines: (J) galectin-I and (K) ICAMI. M/C: Top and bottom sides cultured with RFP+ rMSCs and CP, respectively. C/M: Top and bottom sides cultured with CP and RFP+ rMSCs, respectively. M/X: Top and bottom sides cultured with RFP+ rMSCs and no CP, respectively. X/C: Top and bottom sides cultured with no rMSCs and CP, respectively. N=4 per group. *P<0.05; a, b, and $\mathrm{c}$ indicate significantly different groups. 
LGALS1, ICAM1, CCN3, CCN4, GDF15, and $H G F^{42}$ Wikipathway predictions revealed lung fibrosis (WP3632), IGF-1/Akt signaling (WP3675), chemokine signaling pathway (WP2292), and spinal cord injury (WP2432) as significant pathways (Figure 6 and Table 3). Three cytokines out of 190 - namely, CCL5, HGF, and CXCL2 - were involved in the chemokine signaling pathway (WP2292; 190 genes); 2 out of 31 possible growth factors-ie, IGFBP-3 and IGFBP5-were involved in IGF-1/Akt signaling (WP3675); 3 out of 190 chemokines - ie, CCL22, CCL5, and CXCL2-were involved in the chemokine signaling pathway (WP2292); and 2 cytokines out of 99 (CXCL2 and ICAM1) were involved in spinal cord injury (WP2432) (Table 3).

\section{Discussion}

There is limited understanding of the mechanisms underlying CP regeneration after stroke. In this study, we used ION-labeled MSCs to determine the destination of injected cells and found that they localized to the CP. MSCs labeled with IONs maintain the capacity for proliferation, differentiation, and reactive oxygen species production as well as mitochondrial membrane potential. ${ }^{8}$ These cells are easily identified not only by MRI but also by light microscopy, which facilitates the identification of BM-derived cells that have migrated to the leptomeninges, ${ }^{22} \mathrm{CP}^{23}$ and perivascular spaces. ${ }^{22}$ In the stroke brain, MSCs are detected at the infarct site, injection site, and $\mathrm{CC} ;{ }^{24-26}$ however, our study provides the first evidence that injected MSCs are trafficked to the $\mathrm{CP}$ based on MRI and PB staining (Figures 1 and 2; Tables 1 and 2). Moreover, the migration of MSCs occurred at a very early stage after injection (day 1) (Figure 2). These findings suggest new possibilities for cell delivery methods in cell-based therapy, as intravenous delivery is used in clinical trials but direct injection into the brain is preferred in animal studies. ${ }^{4}$ The observation that MSCs and CP interact and mutually enhance proliferation may also explain why results obtained in preclinical studies do not translate well to clinical studies.

The successful establishment of our rat stroke model was confirmed by MRI (Figure 1A), the corner test (Figure

Table 3 Pathway Prediction with Enrichr

\begin{tabular}{|c|c|c|c|c|c|}
\hline Term & Overlap & $\begin{array}{l}\text { Adjusted } \\
\text { P-value }\end{array}$ & $\begin{array}{l}\text { Odds } \\
\text { Ratio }\end{array}$ & $\begin{array}{l}\text { Combined } \\
\text { Score }\end{array}$ & Genes \\
\hline Lung fibrosis (WP3632) & $3 / 61$ & $7.70 \mathrm{E}-04$ & 89.42 & 1103.35 & $\begin{array}{l}\text { CCL5; HGF; } \\
\text { CXCL2 }\end{array}$ \\
\hline $\begin{array}{l}\text { Factors and pathways affecting insulin-like growth factor (IGFI)-Akt } \\
\text { signaling (WP3675) }\end{array}$ & $2 / 31$ & I.I2E-02 & 117.30 & 1052.57 & IGFBP5; IGFBP3 \\
\hline Chemokine signaling pathway (WP2292) & $3 / 190$ & $7.72 \mathrm{E}-03$ & 28.71 & 256.52 & $\begin{array}{l}\text { CCL22; CCL5; } \\
\text { CXCL2 }\end{array}$ \\
\hline Spinal cord injury (WP2432) & $2 / 99$ & $5.70 \mathrm{E}-02$ & 36.73 & 244.21 & CXCL2; ICAMI \\
\hline Myometrial relaxation and contraction pathways (WP385) & $2 / 153$ & $\mathrm{I} .08 \mathrm{E}-0 \mathrm{I}$ & 23.77 & 137.63 & IGFBP5; IGFBP3 \\
\hline PluriNetWork (WPI763) & $2 / 292$ & $3.14 \mathrm{E}-0 \mid$ & 12.45 & 56.49 & IGFBP3; ICAMI \\
\hline EBV LMPI signaling (WPI243) & $1 / 22$ & $3.03 \mathrm{E}-0 \mathrm{I}$ & 82.64 & 365.27 & CCL5 \\
\hline Type II interferon signaling (IFNG) (WPI253) & $1 / 34$ & $4.08 \mathrm{E}-0 \mathrm{I}$ & 53.48 & 213.23 & ICAMI \\
\hline Signaling of hepatocyte growth factor receptor (WPI 93) & $1 / 34$ & $3.63 \mathrm{E}-0 \mathrm{I}$ & 53.48 & 213.23 & HGF \\
\hline p53 signaling (WP2902) & $1 / 67$ & $6.38 \mathrm{E}-0 \mathrm{I}$ & 27.14 & 90.02 & IGFBP3 \\
\hline IL-5 signaling pathway (WPI5I) & $1 / 69$ & $5.97 \mathrm{E}-0 \mathrm{I}$ & 26.35 & 86.65 & ICAMI \\
\hline IL-2 signaling pathway (WP450) & $\mathrm{I} / 76$ & $6.02 \mathrm{E}-0 \mathrm{I}$ & 23.92 & 76.40 & ICAMI \\
\hline Delta-notch signaling pathway (WP265) & $1 / 83$ & $6.06 \mathrm{E}-0 \mathrm{I}$ & 21.91 & 68.07 & CCN3 \\
\hline Focal adhesion (WP85) & $1 / 185$ & $1.00 \mathrm{E}+00$ & 9.83 & 22.91 & HGF \\
\hline Focal adhesion-PI3K-Akt-mTOR-signaling pathway (WP284I) & $1 / 324$ & $1.00 \mathrm{E}+00$ & 5.61 & 10.13 & HGF \\
\hline
\end{tabular}


3A), and mNSS (Figure 3B). Traditionally, stroke in animal models is confirmed by 2,3,5-triphenyltetrazolium chloride (TTC) staining; however, MRI can be used instead as it shows a high degree of correlation with TTC staining results and reduces the number of animals used in experiments. ${ }^{44-46}$

IONs can stimulate cell proliferation, which may contribute to the restoration of brain function in stroke models. ${ }^{47}$ Long-term observation by MRI revealed the fate of IONlabeled MSCs in the present study. These advantages make ION-labeled stem cells a promising reagent for cell-based therapies. There is growing concern regarding the stemness of the ION-labeled stem cells since some of them stimulate reactive oxygen species production and/or interfere the mitochondrial membrane potential. ${ }^{48,49}$ We previously investigated the reactive oxygen species production and mitochondrial membrane potential interference of Ferucarbotran labeled MSCs and there is no difference before and after Ferucarbotran labeling. There is no transfecting agent such as poly-lysine needed for Ferucarbotran labeling that might contribute to the finding. ${ }^{50,51}$

Trophic factors are involved in cell maintenance, regeneration, and repair, and enhance the therapeutic effects of injected stem cells following stroke. ${ }^{52}$ MSCs secrete chemokines, growth factors, and cytokines, ${ }^{12-15,20}$ while the $\mathrm{CP}$ secretes factors that promote tissue maintenance and repair ${ }^{29-31}$ and recruit immune cells. ${ }^{32} \mathrm{We}$ investigated changes in cytokine levels in co-cultures of MSCs and CP and found that multiple factors involved in proliferation and cell adhesion were altered (Figures 5C and 6) including NOV/CCN3, WISP-1/CCN4, and CCL22, which may be involved in the recruitment of MSCs to the CP (Figures 5C and 6G-I). MSCs secrete IGF-1, HGF, and GDF-15, ${ }^{20}$ but the involvement of IGFBP-3 and IGFBP-5 has not been previously reported. IGFBP-3 and IGFBP-5 bind and stabilize IGF-1 to induce proliferation. ${ }^{53}$ Moreover, IGF-1 has demonstrated neuroprotective effects in stroke. ${ }^{54}$ Although IGF-1 level was unchanged in $\mathrm{MSC} / \mathrm{CP}$ co-cultures (Figure S2), IGFBP-3 and IGFBP-5 were upregulated (Figures $5 \mathrm{C}$ and $6 \mathrm{~B}, \mathrm{C}$ ).

To determine whether the different materials of the transwell and co-culture dishes affected our results, we performed the transwell assay with either the MSCs or $\mathrm{CP}$ at the top and found that the cytokine profiles determined by cytokine array showed slight variations depending on the configuration but were largely similar (Figure 5). The differences may be attributable to the material or size of the dish. CCL3 and IGFBP-2 were mainly produced by the CP (Figure 5C). CCL3 may attract MSCs to the CP as it has been shown to recruit MSCs to wound sites. ${ }^{55}$ IGFBP-2 is involved in the regulation of corneal fibroblast differentiation. ${ }^{53,56}$ As candidate cytokines were selected based on their level in the $\mathrm{rMSC} / \mathrm{CP}$ co-culture relative to that in a monoculture, CCL3 and IGFBP-2 were not investigated further. Cytokine arrays provide a large amount of information but have some limitations because they include only 79 analytes. Thus, some unknown factors may mediate the interaction between MSCs and CP.

The Wikipathway prediction indicated that lung fibrosis (WP3632), IGF-1/Akt signaling (WP3675), chemokine signaling pathway (WP2292), and spinal cord injury (WP2432) are involved in the effects observed in MSC/ CP co-cultures (Table 3). Lung fibrosis was not relevant to our investigation, but the others warrant further study.

$\mathrm{CP}$ secretomes are involved in neurogenesis and MSC proliferation (Figure 4A). ${ }^{28}$ The levels of HGF, GDF-15, and IGFBP-5 - which have antioxidant, antiapoptotic, and pro-proliferative effects ${ }^{16-18}$ - showed increasing trends in the rMSC/CP co-culture (Figure 6A, C and F). MSCs have demonstrated beneficial effects on motor function, stroke volume, and neurogenesis following stroke. ${ }^{11,19}$ Our results suggest that MSCs may exert these effects through crosstalk with the CP.

\section{Conclusion}

Some ION-labeled MSCs were located in the CP of the ischemic stroke brain. Bidirectional effects on proliferation were observed in MSC and CP co-cultures involving various cytokines and the IGF-1/Akt, chemokine signaling, and spinal cord injury signaling pathways. These findings could shift cell therapy strategies for stroke from intravenous delivery of MSCs to their direct injection into lateral ventricles harboring the $\mathrm{CP}$, which could enhance functional recovery.

\section{Abbreviations}

BDNF, brain-derived neurotrophic factor; bFGF, basic fibroblast growth factor; $\mathrm{BM}$, bone marrow; $\mathrm{CC}$, corpus callosum; CCL, C-C motif chemokine ligand; $\mathrm{CCN}$, cellular communication network factor; $\mathrm{CD}$, cluster of differentiation; CP, choroid plexus; CSF, cerebrospinal fluid; CXCL, C-X-C motif chemokine; DMEM, Dulbecco's Modified Eagle's medium; FGF, fibroblast growth factor; GDF, growth and differentiation factor; GDNF, glial cell line-derived neurotrophic factor; HEK, human embryonic kidney; HGF, hepatocyte growth factor; ICAM, 
intercellular adhesion molecule; IGF, insulin-like growth factor; IGFBP, IGF-binding protein; IL, interleukin; ION, iron oxide nanoparticle; LGALS, lectin, galactosidebinding, soluble (galectin); MCA, middle cerebral artery; MCP, monocyte chemoattractant protein; mNSS, Modified Neurological Severity score; MRI, magnetic resonance imaging; MSC, mesenchymal stem cell; NGF, nerve growth factor; NOV, nephroblastoma overexpressed; NT, neurotropin; PB, Prussian blue; PBS, phosphate-buffered saline; PCA, principal component analysis; RFP, red fluorescent protein; rMSC, rat mesenchymal stem cell; SDF, stromal-derived growth factor; TGF, transforming growth factor; TTC, 2,3,5-triphenyltetrazolium chloride; VEGF, vascular endothelial growth factor; V-SVZ, ventricularsubventricular zone; WISP, WNT1-inducible signaling pathway protein.

\section{Data Sharing Statement}

Cytokine array data in this article are available from the corresponding author upon request.

\section{Acknowledgments}

We thank the 7T Animal MRI Core Laboratory of the Molecular Imaging Center at National Taiwan University for providing access to the facility and technical support. The manuscript was edited by the Charlesworth Author Services.

\section{Author Contributions}

M.-R. W and J.-K. H designed the study. M.-R. W and C.H. L performed the experiments. M.-R. W and J.K. H analyzed the data. M.-R. W and J.-K. H wrote the manuscript. J.-K. H. revised the manuscript and supervised the study. All authors contributed to data analysis, drafting or revising the article, have agreed on the journal to which the article will be submitted, gave final approval of the version to be published, and agree to be accountable for all aspects of the work.

\section{Funding}

This study was supported by grants from the Ministry of Science and Technology of Taiwan (MOST106-2314B-303-007 and MOST107-2314-B-303-006-MY3) and the Buddist Tzu Chi Medical Foundation (TCRD-TPEMOST-106-05, TCRD-TPE-MOST-107-05, and TCRDTPE-MOST-108-04).

\section{Disclosure}

The authors have no conflicts of interest to declare.

\section{References}

1. Feigin VL, Krishnamurthi RV, Theadom AM, et al. Global, regional, and national burden of neurological disorders during 1990-2015: a systematic analysis for the global burden of disease study 2015 . Lancet Neurol. 2017;16(11):877-897. doi:10.1016/S1474-4422(17) 30299-5

2. Song CG, Zhang YZ, Wu HN, et al. Stem cells: a promising candidate to treat neurological disorders. Neural Regen Res. 2018;13 (7):1294-1304. doi:10.4103/1673-5374.235085

3. Lindvall O, Kokaia Z. Stem cells for the treatment of neurological disorders. Nature. 2006;441(7097):1094-1096. doi:10.1038/ nature 04960

4. Squillaro T, Peluso G, Galderisi U. Clinical trials with mesenchymal stem cells: an update. Cell Transplant. 2016;25(5):829-848. doi:10.3727/096368915X689622

5. Trounson A, Thakar RG, Lomax G, et al. Clinical trials for stem cell therapies. BMC Med. 2011;9(1):52. doi:10.1186/1741-7015-9-52

6. Chien L-Y, Hsiao J-K, Hsu S-C, et al. In vivo magnetic resonance imaging of cell tropism, trafficking mechanism, and therapeutic impact of human mesenchymal stem cells in a murine glioma model. Biomaterials. 2011;32(12):3275-3284. doi:10.1016/j. biomaterials.2011.01.042

7. $\mathrm{Lu} \mathrm{CW}$, Hsiao JK, Liu HM, et al. Characterization of an iron oxide nanoparticle labelling and MRI-based protocol for inducing human mesenchymal stem cells into neural-like cells. Sci Rep. 2017;7(1)

8. Hsiao JK, Tai MF, Chu HH, et al. Magnetic nanoparticle labeling of mesenchymal stem cells without transfection agent: cellular behavior and capability of detection with clinical $1.5 \mathrm{~T}$ magnetic resonance at the single cell level. Magn Reson Med. 2007;58(4):717-724. doi:10.1002/mrm.21377

9. Kan I, Barhum Y, Melamed E, et al. Mesenchymal stem cells stimulate endogenous neurogenesis in the subventricular zone of adult mice. Stem Cell Rev Reports. 2011;7(2):404-412. doi:10.1007/ s12015-010-9190-x

10. Alvarez-Buylla A, García-Verdugo JM. Neurogenesis in adult subventricular zone. $J$ Neurosci. 2002;22(3):629-634. doi:10.1523/ JNEUROSCI.22-03-00629.2002

11. Cunningham CJ, Redondo-Castro E, Allan SM. The therapeutic potential of the mesenchymal stem cell secretome in ischaemic stroke. J Cereb Blood Flow Metab. 2018;38(8):1276-1292. doi:10.1177/0271678X18776802

12. Park CW, Kim KS, Bae S, et al. Cytokine secretion profiling of human mesenchymal stem cells by antibody array. Int J Stem Cells. 2009;2(1):59-68. doi:10.15283/ijsc.2009.2.1.59

13. Nakano N, Nakai Y, Seo TB, et al. Characterization of conditioned medium of cultured bone marrow stromal cells. Neurosci Lett. 2010;483(1):57-61. doi:10.1016/j.neulet.2010.07.062

14. Schinköthe T, Bloch W, Schmidt A. In vitro secreting profile of human mesenchymal stem cells. Stem Cells Dev. 2008;17 (1):199-205. doi:10.1089/scd.2007.0175

15. Kupcova Skalnikova H. Proteomic techniques for characterisation of mesenchymal stem cell secretome. Biochimie. 2013;95 (12):2196-2211. doi:10.1016/j.biochi.2013.07.015

16. Li H, Jiang $\mathrm{T}$, Lin $\mathrm{Y}$, et al. HGF protects rat mesangial cells from high-glucose-mediated oxidative stress. Am J Nephrol. 2006;26 (5):519-530. doi:10.1159/000097368

17. Sanada F, Taniyama Y, Muratsu J, et al. IGF binding protein-5 induces cell senescence. Front Endocrinol (Lausanne). 2018;9 (FEB):1. doi:10.3389/fendo.2018.00053 
18. Tiwari KK, Moorthy B, Lingappan K. Role of GDF15 (growth and differentiation factor 15) in pulmonary oxygen toxicity. Toxicol in Vitro. 2015;29(7):1369-1376. doi:10.1016/j.tiv.2015.05.008

19. Chrostek MR, Fellows EG, Crane AT, et al. Efficacy of stem cell-based therapies for stroke. Brain Res. 2019;1722:146362. doi:10.1016/j.brainres.2019.146362

20. Pittenger MF, Discher DE, Péault BM, et al. Mesenchymal stem cell perspective: cell biology to clinical progress. Npj Regen Med. 2019;4 (1):1-15.

21. Negoro T, Okura H, Maehata M, et al. Trends in clinical trials for stroke by cell therapy: data mining ClinicalTrials.gov and the ICTRP portal site. Npj Regen Med. 2019;4(1):1-10. doi:10.1038/s41536019-0082-7

22. Vallières L, Sawchenko PE. Bone marrow-derived cells that populate the adult mouse brain preserve their hematopoietic identity. $J$ Neurosci. 2003;23(12):5197-5207. doi:10.1523/JNEUROSCI.2312-05197.2003

23. Hasegawa-Ishii S, Shimada A, Inaba M, et al. Selective localization of bone marrow-derived ramified cells in the brain adjacent to the attachments of choroid plexus. Brain Behav Immun. 2013;29:82-97. doi:10.1016/j.bbi.2012.12.010

24. Duan X, Lu L, Wang Y, et al. The long-term fate of mesenchymal stem cells labeled with magnetic resonance imaging-visible polymersomes in cerebral ischemia. Int J Nanomedicine. 2017;12:6705-6719. doi:10.2147/IJN.S146742

25. Jang KS, Lee KS, Yang SH, et al. In vivo tracking of transplanted bone marrow-derived mesenchymal stem cells in a murine model of stroke by bioluminescence imaging. $J$ Korean Neurosurg Soc. 2010;48(5):391-398. doi:10.3340/jkns.2010.48.5.391

26. Wang $\mathrm{Y}, \mathrm{Xu} \mathrm{F}$, Zhang $\mathrm{C}$, et al. High MR sensitive fluorescent magnetite nanocluster for stem cell tracking in ischemic mouse brain. Nanomedicine. 2011;7(6):1009-1019. doi:10.1016/j. nano.2011.03.006

27. Hamisha KN, Tfilin M, Yanai J, et al. Mesenchymal stem cells can prevent alterations in behavior and neurogenesis induced by Aß25-35 administration. J Mol Neurosci. 2015;55(4):1006-1013. doi:10.1007/ s12031-014-0457-6

28. Silva-Vargas V, Maldonado-Soto AR, Mizrak D, et al. Age-dependent niche signals from the choroid plexus regulate adult neural stem cells. Cell Stem Cell. 2016;19(5):643-652. doi:10.1016/j.stem.2016.06.013

29. Stopa EG, Berzin TM, Kim S, et al. Human choroid plexus growth factors: what are the implications for CSF dynamics in Alzheimer's disease? Exp Neurol. 2001;167(1):40-47. doi:10.1006/ exnr.2000.7545

30. Aleshire SL, Hajdu I, Bradley CA, et al. Choroid plexus as a barrier to immunoglobulin delivery into cerebrospinal fluid. J Neurosurg. 1985;63(4):593-597. doi:10.3171/jns.1985.63.4.0593

31. Johanson CE, Palm DE, Primiano MJ, et al. Choroid plexus recovery after transient forebrain ischemia: role of growth factors and other repair mechanisms. Cell Mol Neurobiol. 2000;20(2):197-216. doi:10.1023/A:1007097622590

32. Meeker RB, Williams K, Killebrew DA, et al. Cell trafficking through the choroid plexus. Cell Adh Migr. 2012;6(5):390-396. doi:10.4161/cam.21054

33. Xiang J, Routhe LJ, Andrew Wilkinson D, et al. The choroid plexus as a site of damage in hemorrhagic and ischemic stroke and its role in responding to injury. Fluids Barriers CNS. 2017;14(1). doi:10.1186/ s12987-017-0056-3.

34. Borlongan CV, Skinner SJM, Geaney M, et al. Intracerebral transplantation of porcine choroid plexus provides structural and functional neuroprotection in a rodent model of stroke. Stroke. 2004;35 (9):2206-2210. doi:10.1161/01.STR.0000138954.25825.0b

35. Tiscornia G, Singer O, Verma IM. Production and purification of lentiviral vectors. Nat Protoc. 2006;1(1):241-245. doi:10.1038/ nprot.2006.37
36. Anon. American Physiological Society \&gt. Guiding principles for the care and use of vertebrate animals in research and training. Available from: https://www.physiology.org/career/policy-advocacy/ policy-statements/care-and-use-of-vertebrate-animals-in-research? $\mathrm{SSO}=\mathrm{Y}$.

37. Chen S-F, Hsu C-W, Huang W-H, et al. Post-injury baicalein improves histological and functional outcomes and reduces inflammatory cytokines after experimental traumatic brain injury. Br J Pharmacol. 2008;155(8):1279-1296. doi:10.1038/ bjp. 2008.345

38. Bang OY, Moon GJ, Kim DH, et al. Stroke induces mesenchymal stem cell migration to infarcted brain areas via CXCR4 and C-met signaling. Transl Stroke Res. 2017;8(5):449-460. doi:10.1007/ s12975-017-0538-2

39. Zhang L, Schallert T, Zhang ZG, et al. A test for detecting long-term sensorimotor dysfunction in the mouse after focal cerebral ischemia. $J$ Neurosci Methods. 2002;117(2):207-214. doi:10.1016/S01650270(02)00114-0

40. Rueden CT, Schindelin J, Hiner MC, et al. ImageJ2: imageJ for the next generation of scientific image data. BMC Bioinform. 2017;18 (1):529. doi:10.1186/s12859-017-1934-z

41. Metsalu T, ClustVis VJ. A web tool for visualizing clustering of multivariate data using principal component analysis and heatmap. Nucleic Acids Res. 2015;43(W1):W566-W570. doi:10.1093/nar/ gkv468

42. Kuleshov MV, Jones MR, Rouillard AD, et al. Enrichr: a comprehensive gene set enrichment analysis web server 2016 update. Nucleic Acids Res. 2016;44(W1):W90-W97. doi:10.1093/ nar/gkw377

43. Chen EY, Tan CM, Kou Y, et al. Enrichr: interactive and collaborative HTML5 gene list enrichment analysis tool. BMC Bioinform. 2013;14(1):128. doi:10.1186/1471-2105-14-128

44. Koch S, Mueller S, Foddis M, et al. Atlas registration for edema-corrected MRI lesion volume in mouse stroke models. J Cereb Blood Flow Metab. 2019;39(2):313-323. doi:10.1177/ $0271678 X 17726635$

45. Kurozumi K, Nakamura K, Tamiya T, et al. Mesenchymal stem cells that produce neurotrophic factors reduce ischemic damage in the rat middle cerebral artery occlusion model. Mol Ther. 2005;11 (1):96-104. doi:10.1016/j.ymthe.2004.09.020

46. Yang Y, Gao K, Hu Z, et al. Autophagy upregulation and apoptosis downregulation in DAHP and triptolide treated cerebral ischemia. Mediators Inflamm. 2015;2015:120198. doi:10.1155/2015/120198

47. Huang D-M, Hsiao J-K, Chen Y-C, et al. The promotion of human mesenchymal stem cell proliferation by superparamagnetic iron oxide nanoparticles. Biomaterials. 2009;30(22):3645-3651. doi:10.1016/j. biomaterials.2009.03.032

48. Lee S, Park D, Yun WS, et al. Endocytic trafficking of polymeric clustered superparamagnetic iron oxide nanoparticles in mesenchymal stem cells. J Control Release. 2020;326.

49. Ahn YJ, Kong TH, Choi JS, et al. Strategies to enhance efficacy of SPION-labeled stem cell homing by magnetic attraction: a systemic review with meta-analysis. Int J Nanomedicine. 2019;14:4849-4866. doi:10.2147/IJN.S204910

50. Yang C-Y, Tai M-F, Chen S-T, et al. Labeling of human mesenchymal stem cell: comparison between paramagnetic and superparamagnetic agents. J Appl Phys. 2009;105(7):07B314. doi:10.1063/1.3072821

51. Hsiao J-K, Yang C-Y, Wang Y-H, et al. Magnetic nanoparticle labeling of cultured cancer cell line without transfection agent. Biomed Eng Appl Basis Commun. 2008;20(4):259-265. doi:10.4015/ S1016237208000854

52. van Velthoven CTJ, Sheldon RA, Kavelaars A, et al. Mesenchymal stem cell transplantation attenuates brain injury after neonatal stroke. Stroke. 2013;44(5):1426-1432. doi:10.1161/STROKEAHA.111.000 326 
53. Zumkeller W, Westphal M. The IGF/IGFBP system in CNS malignancy. J Clin Pathol. 2001;54(4):227-229. doi:10.1136/ mp.54.4.227

54. Serhan A, Boddeke E, Kooijman R. Insulin-like growth factor-1 is neuroprotective in aged rats with ischemic stroke. Front Aging Neurosci. 2019;11:349. doi:10.3389/fnagi.2019.00349

55. Hocking AM. The role of chemokines in mesenchymal stem cell homing to wounds. Adv Wound Care. 2015;4(11):623-630. doi:10.1089/wound.2014.0579
56. Park SH, Kim KW, Kim JC. The role of insulin-like growth factor binding protein 2 (IGFBP2) in the regulation of corneal fibroblast differentiation. Investig Ophthalmol Vis Sci. 2015;56(12):7293-7302. doi:10.1167/iovs.15-16616

\section{Publish your work in this journal}

The International Journal of Nanomedicine is an international, peerreviewed journal focusing on the application of nanotechnology in diagnostics, therapeutics, and drug delivery systems throughout the biomedical field. This journal is indexed on PubMed Central, MedLine, CAS, SciSearch ${ }^{\circledR}$, Current Contents ${ }^{\circledR} /$ Clinical Medicine, $^{2}$
Journal Citation Reports/Science Edition, EMBase, Scopus and the Elsevier Bibliographic databases. The manuscript management system is completely online and includes a very quick and fair peer-review system, which is all easy to use. Visit http://www.dovepress.com/ testimonials.php to read real quotes from published authors.

Submit your manuscript here: https://www.dovepress.com/international-journal-of-nanomedicine-journal 